\title{
PELATIHAN MANAGEMENT DISASTER GEMPA BUMI UNTUK MAHASISWA SIAGA BENCANA (PERWAGANA) BENGKULU
}

\author{
Ida Rahmawati $^{1 *}$; Vike Pebri Giena ${ }^{2}$; Dwi Putri Sulistyaningsih ${ }^{3}$; Rina Aprianti ${ }^{4}$ \\ 1,2,3,4 STIKES Tri Mandiri Sakti Bengkulu \\ *Korespondensi : idarahmawati1608@gmail.com
}

\begin{abstract}
ABSTRAK
Latar belakang : Provinsi Bengkulu merupakan salah satu wilayah di Indonesia yang berisiko terkena gempa bumi dan tsunami karena terletak di pesisir Samudera Hindia. Lokasi tersebut merupakan pertemuan dua lempeng besar dan berada dekat zona subduksi tektonik Sunda yang sewaktu-waktu dapat bertabrakan. Dalam upaya mencegah terjadinya bencana, diperlukan kesiapsiagaan dari setiap sektor termasuk perguruan tinggi untuk mengurangi risiko bencana. Tujuan: meningkatkan pengetahuan mahasiwa Perhimpunan Mahasiswa Siaga Bencana (PERWAGANA) mengenai manajemen bencana gempa bumi. Metode: terdiri dari empat sesi yaitu: pre test, ceramah, praktek, dan post test. Penyerahan materi dilakukan dengan cara ceramah dan melakukan keterampilan penanggulangan bencana gempa bumi. Hasil: pengetahuan mahasiswa meningkat setelah diberikan pelatihan mngemen disaster gempa bumi. Kesimpulan: Penanggulangan bencana gempa merupakan salah satu upaya pencegahan dan tindakan preventif yang dilakukan oleh dosen STIKES Tri Mandiri Sakti melalui kegiatan edukasi kesehatan dan simulasi dengan sasaran mahasiswa agar siap turun ke lapangan.
\end{abstract}

Keywords: gempa bumi, mahasiswa siaga bencana, manajemen bencana 


\section{PENDAHULUAN}

Indonesia merupakan Negara yang sangat rawan terhadap bencana alam karena di kelilingi oleh lautan dan samudera. Secara geografis wilayah Indonesia terletak pada pertemuan empat lempeng tektonik yaitu lempeng samudera Hindia, samudera pasifik, lempeng benua Asia dan benua Australia (Departemen Kesehatan RI, 2007) sehingga rentan terhadap gempa bumi dan tsunami. Gempa bumi merupakan getaran dari dalam bumi yang merambat ke permukaan disebabkan karena akivitas tektonik, vulkanik, dan penyebab alam lainnya (Nur, 2010). United States Geological Survey (USGS) dan National Oceanic (NOAA) menyebutkan bahwa Indonesia pada tahun 1800-2014 mengalami gempa bumi sebanyak 262 dengan rata-rata magnitude sebesar 5-9,1 (Adzhari, Widjasna, \& Kurniawan, 2016).

Provinsi Bengkulu berbatasan dengan Samudera Indonesia pada garis pantai sepanjang 433. Ibu kota Provinsi Bengkulu adalah Kota Bengkulu dengan luas wilayah 19.788,70 km. Kota Bengkulu terletak dekat dengan zona subduksi tekonik sunda dan memiliki cuaca yang lembab dan kering. Data dari Badan Nasional Penagulangan Bencana (BNPB) Tahun 2013 Kota Bengkulu berada di peringkat 168 dari 496 Kabupaten atau Kota dengan indeks risiko bencana sebesar 170 (kategori tinggi). Dengan ancaman terbesar adalah gempa bumi dan tsunami (Fathani, Daly, Glassey, \& Wilopo, 2015). Upaya Pemerintah Provinsi dan Kota yang dilakukan untuk mengurangi resiko bencana adalah dengan memperkirakan daerah-daerah yang akan terkena tsunami. Model ini dibuat berdasarkan gempa-gempa besar yang pernah terjadi di wilayah Bengkulu (Gaffar, 2007).

Upaya yang dilakukan Pemerintah setempat di rasa kurang berpengaruh terhadap masyarakat dan awam. Sehingga di perlukan mitigasi bencana yang bertujuan untuk memberikan pendidikan maupun promosi kesehatan berkaitan dengan kebencanaan secara langsung. Sasaran mitigasi bencana meliputi seluruh usia, karena bencana tidak mengenal usia, jenis kelamin, pangkat dan golongan. Oleh sebab itu diperlukan penguatan mitigasi bencana melalui lembaga pemerintah, Instansi, sekolah dan perguruan tinggi. Instansi kelembagaan dapat melakukan simulasi bencana. Sekolah dapat membentuk sekolah siaga bencana, serta perguruan tinggi dapat mempersiapkan mahasiswanya agar siap membantu masyarakat menghadapi bencana. Karena sifat 
bencana alam yang tidak dapat diprediksi secara cepat, tanpa pernah berhenti, mengancam nyawa, dan mengakibatkan penderitaan, maka diperlukan paradigma respon yang cepat dan efektif bagi setiap individu (Nazli, Sipon, \& Radzi, 2014).

STIKES Tri Mandiri Sakti Bengkulu (TMS) merupakan salah satu perguruan tinggi swasta terletak di Kota Bengkulu mempunyai peran yang cukup penting dalam penanganan bencana. STIKES TMS telah memiliki sistem penangulangan bencana internal dengan membuat Persatuan Mahasiswa Siaga Bencana (PERWAGANA) pada tingkat kemahasiswaan. PERWAGANA dibentuk di bawah naungan Badan Eksekutif Mahasiswa (BEM) karena kebutuhan adanya relawan lapangan untuk terjun ke daerah yang terdampak bencana seperti gempa bumi, tsunami banjir, tanah longsor, dan puting beliung. Dalam upaya mempersiapkan mahasiswa yang tanggap dan siap jika diperlukan saat bencana, maka pelatihan dan simulasi mengenai managemen disaster khususnya gempa bumi sangat diperlukan untuk meningkatkan keterampilan dan mempersiapkan mahasiswa yang tangguh bencana.

PERWAGANA yang dibentuk oleh STIKES Tri Mandiri Sakti siap membantu pemerintah setempat dalam upaya mengurangi dampak bencana alam. Kegiatan yang dilakukan bertujuan untuk peningkatan kapasitas penguragan risiko bencana dengan pendidikan kesehatan dan simulasi kebencanaan gempa bumi.

\section{METODE}

Kegiatan pengabdian ini diberikan pada mahasiswa anggota PERWAGANA, lokasi kegiatan dilaksanakan di STIKES Tri Mandiri Sakti Bengkulu. Kegiatan dilakukan pada tanggal 26 November 2019. Tujuan kegiatan ini adalah meningkatkan pengetahuan anggota PERWAGANA mengenai managemen disaster khususnya gempa bumi. Populasi dan sampel adalah seluruh anggota PERWAGANA sejumlah 15 orang. Dasar dilakukan pelatihan adalah program rutin dari kegiatan UKM Perwagana setiap tahunnya, dan berdasar latar belakang geografis provinsi Bengkulu yang berada pada garis pantai Samudera Hindia, sehingga penting dilakukan pelatihan untuk meningkatkan pengetahuan mahasiswa. Pelaksanaan pelatihan terdiri dari empat sesi, yaitu : pre test, ceramah, praktik, dan post test. Pre test dilakukan dengan memberikan kuesioner mengenai bencana gempa bumi berisi 10 pertanyaan. Setelah pre test selesai, 
peserta mendapatkan materi dari narasumber. Narasumber berasal dari dosen Keperawatan dan Kesehatan Masyarakat. Penyampaian materi dilakukan dengan cara ceramah di kelas dan demonstrasi keterampilan management disaster gempa bumi di laboratorium terpadu dan lapangan kampus. Setelah materi dan demonstrasi, mahasiswa kemudian di ukur pengetahuannya dengan mengisi soal post test terdiri dari 10 pertanyaan. Setelah data terkumpul kemudian dilakukan analisis dengan metode deskriptif sederhana untuk mengetahui rata-rata pengetahuan sebelum dan sesudah pelatihan

\section{HASIL dan PEMBAHASAN}

Karakteristik responden disajikan pada tabel 1 berikut :

Tabel 1 karakteristik responden PERWAGANA STIKES TMS BENGKULU

\begin{tabular}{ccc}
\hline Usia & f & \% \\
\hline $18-20$ & 6 & 40 \\
$21-22$ & 9 & 60 \\
$>22$ & 0 & 0 \\
Total & 15 & 100 \\
& & \\
Jenis Kelamin & $\mathbf{f}$ & $\mathbf{\%}$ \\
Laki-laki & 8 & 53,3 \\
Perempuan & 7 & 46,7 \\
\hline Total & 15 &
\end{tabular}

Sumber : data primer 2019

Berdasarkan tabel karakterisktik responden diatas, didapatkan data bahwa sebagian besar responden berusia 21-22 tahun sebanyak 9 orang. Dan sebagian besar berjenis kelamin Laki-laki sebanyak 8 orang.

Tabel 2 Tingkat Pengetahuan sebelum dan setelah pelatihan Managemen Disaster PERWAGANA STIKES TMS Bengkulu

\begin{tabular}{ccccc}
\hline Tingkat & \multicolumn{2}{c}{ Pre Test } & \multicolumn{3}{c}{ Post Test } \\
Pengetahuan & $\mathrm{f}$ & $\%$ & $\mathrm{f}$ & $\%$ \\
\hline Baik & 0 & 0 & 3 & 20 \\
Cukup & 0 & 0 & 10 & 66,7 \\
Kurang & 15 & 100 & 2 & 13,3 \\
\hline Total & 15 & 100 & 15 & 100
\end{tabular}

Sumber : data primer 2019 
Berdasarkan tabel 2 diketahui bahwa pengetahuan mahasiswa PERWAGANA sebelum dilakukan pelatihan berada pada tingkat kurang sebanyak 15 orang. Setelah di lakukan pelatihan pengetahuan meningkat menjadi cukup sebanyak 10 orang.

Tabel 3 rata-rata nilai pengetahuan sebelum dan sesudah pelatihan Managemen Disaster

\begin{tabular}{ccccc}
\hline Tingkat & \multicolumn{2}{c}{ Pre Test } & \multicolumn{2}{c}{ Post Test } \\
Pengetahuan & $\mathrm{f}$ & $\%$ & $\mathrm{f}$ & $\%$ \\
\hline Baik & 0 & 0 & 3 & 20 \\
Cukup & 0 & 0 & 10 & 66,7 \\
Kurang & 15 & 100 & 2 & 13,3 \\
Total & 15 & 100 & 15 & 100 \\
\hline
\end{tabular}

Sumber : data primer 2019

Kegiatan pelatihan ini bertujuan meningkatkan pengetahuan mahasiwa PERWAGANA mengenai manajemen bencana gempa bumi. Hal ini penting dilakukan mengingat sebagian besar mahasiswa STIKES Tri Mandiri Sakti merupakan warga asli Provinsi Bengkulu, dan Provinsi Bengkulu berada pada garis pantai Samudera Hindia tempat bertemunya lempeng tektonik yang beresiko terhadap gempa dan tsunami. Sehingga mahasiswa perlu dibekali pengetahuan yang cukup mengenai manajemen bencana.

Pengetahuan dasar mengenai manajemen bencana perlu diberikan kepada kalangan mahasiwa di perguruang tinggi. Sesuai dengan pendapat penelitian yang menyatakan bahwa melalui perguruan tinggi penanggulan bencana di nilai efekif dalam upaya pengurangan risiko bencana (Nur'aeni, Anna, Prawesti, Emaliyawati, \& Mirwanti, 2017). Pemberian pendidikan kesehatan juga efektif diberikan pada mahasiswa yang berada pada tingkat usia remaja akhir, karena usia ini dirasa mampu menyerap pengetahuan dengan baik. hal ini sesuai dengan penelitian Dariyo (2004) mengatakan mahasisa merupakan sebagai seorang yang memasuki masa perkembangan remaja akhir, dalam konteks perkembangan kognitif mereka dapat melakukan kegiatan berfikir yang rasional, logis, sistematis, terstruktur, dan hipotesis.

Indonesia merupakan salah satu Negara di wilayah Asia Tenggara yang sangat rentan terhadap bencana alam berulang kali, bencana yang terjadi menyebabkakn kerusakan pada kehidupan manusia dan harta benda (Lai, He, Tan, \& Phua, 2009). Mitigasi merupakan salah satu upaya yang dapat dilakukan oleh semua pihak baik 
pemerintah maupun masyarakat melalui pembangunan secara fisik, penyadaran, peningkatan kemampuan menghadapi bencana (Nur'aeni et al., 2017) dan melakukan pemetaan wilayah dan melakukan kajian resiko bencana (Gaffar, 2007). Upaya tersebut dirasa masih kurang cukup, diperlukan pendekatan langsung kepada masyarakat baik umum maupun siswa sekolah, perguruan tinggi agar sadar dan mampu mendeteksi dini dari bahaya bencana.

Hasil penelitian menunjukan pada umumnya pengetahuan mengenai manajemen bencana pada mahasiswa PERWAGANA sudah cukup baik, hal ini di tunjukan dengan rentang pengetahuan sebagian besar pada tingkat "cukup" dan " baik". faktor ini dapat disebabkan karena sebelumnya mahasiwa pernah mendapatkan teori di bangku kuliah dan terjun langsung saat terjadi bencana. Penelitian (Ahayalimudin, Ismail, \& Saiboon, 2012) menunjukan bahwa pengetahuan baik yang dimiliki seseorang dapat dipengaruhi oleh program pendidikan dan pelatihan kebencanaan sebelumnya yang didapat. Hal ini didukung oleh (Nur'aeni et al., 2017) dalam penelitiannya menyebutkan mahasiwa yang telah diberikan pelatihan manajemen bencana mempunyai pengetahuan dengan level sedang karena sebagian besar peseta sudah pernah terlibat langsung dalam upaya penangulangan bencana. Pada hasil pre tes mahasiwa menunjukan pengetahuan yang kurang secara keseluruhan, hal ini dapat disebabkan karena kurangnya persiapan dalam rangkaian cara pelatihan, dan sebelumnya mahasiwa merupakan relawan (volunter) pada bencana banjir, sehingga pengetahuan mengenai manajemen bencana gempa bumi masih kurang.

\section{Simpulan}

Pengetahuan mahasiswa meningkat setelah diberikan pelatihan managemen disaster gempa bumi. Penanggulangan bencana gempa merupakan salah satu upaya pencegahan dan tindakan preventif yang dilakukan oleh dosen STIKES Tri Mandiri Sakti melalui kegiatan edukasi kesehatan dan simulasi dengan sasaran mahasiswa agar siap turun ke lapangan.

\section{Ucapan Terimakasih}

Terimakasih kepada semua pihak yang telah banyak membantu dalam proses pelaksanaan kegiatan pengabdian masyarakat ini. 


\section{DAFTAR PUSTAKA}

Adzhari, F. R., Widjasna, B., \& Kurniawan, Bi. (2016). Analisis implementasi manajemen pelatihan kesiapan petugas tanggap darurat dalam menghadapi bencana gempa bumi pada gedung instalasi rawat inap (IRNA I) di RSUP Dr. Sardjito Yogyakarta. Jurnal Kesehatan Masyarakat, 4(4), 659-666. Retrieved from http://ejournal-s1.undip.ac.id/index.php/jkm

Ahayalimudin, N., Ismail, A., \& Saiboon, I. M. (2012). Disaster management: a study on knowledge, attitude and practice of emergency nurse and community health nurse. BMC Public Health, 12(S2), 2458. https://doi.org/10.1186/1471-2458-12s2-a3

Dariyo, A. (2004). Pengetahuan Tentang Penelitian Dan Motivasi Belajar Pada Mahasiswa. Jurnal Psikologi, 2(1), 44.

Departemen Kesehatan RI. (2007). Pedoman Teknis Penanggulangan Krisis Kesehatan Akibat Bencana. Jakarta.

Fathani, T. F., Daly, M., Glassey, P., \& Wilopo, W. (2015). Profil Kota BengkuluKerentanan Bencana Alam. Yogyakarta.

Gaffar, E. Z. (2007). Pemetaan dan Kajian Bencana Tsunami Daerah Kota Bengkulu (Vol. 177, pp. 978-979). Bandung.

Lai, A. Y., He, J. A., Tan, T. B., \& Phua, K. H. (2009). A proposed ASEAN disaster response, training and logistic centre enhancing regional governance in disaster management. Transition Studies Review, 16(2), 299-315. https://doi.org/10.1007/s11300-009-0068-z

Nazli, N. N. N. N., Sipon, S., \& Radzi, H. M. (2014). Analysis of Training Needs in Disaster Preparedness. Procedia - Social and Behavioral Sciences, 140, 576-580. https://doi.org/10.1016/j.sbspro.2014.04.473

Nur'aeni, A., Anna, A., Prawesti, A., Emaliyawati, E., \& Mirwanti, R. (2017). Pelatihan Manajemen Bencana Bagi Anggota Padjadjaran Nursing Corps (PNC). Jurnal Bagimu Negeri, 1(2), 71. https://doi.org/10.26638/jbn.415.8651

Nur, A. M. (2010). Gempa Bumi, Tsunami Dan Mitigasinya. Gempa Bumi, Tsunami Dan Mitigasinya, 7(1). https://doi.org/10.15294/jg.v7i1.92 